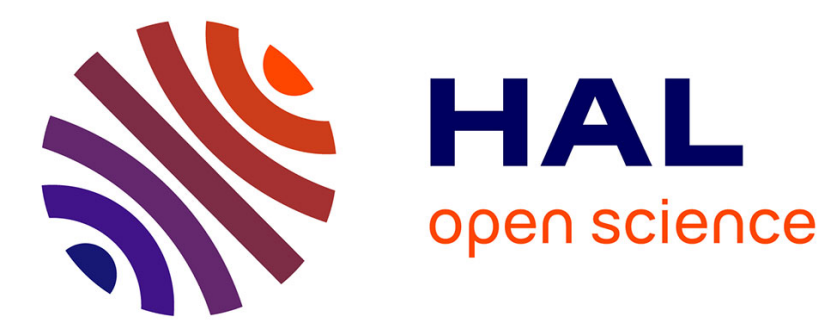

\title{
Cruciform shape benefits for experimental and numerical evaluation of sheet metal formability
}

Lionel Leotoing, Dominique Guines, Ibrahim Zidane, Eric Ragneau

\section{To cite this version:}

Lionel Leotoing, Dominique Guines, Ibrahim Zidane, Eric Ragneau. Cruciform shape benefits for experimental and numerical evaluation of sheet metal formability. Journal of Materials Processing Technology, 2013, 213, pp.856-863. 10.1016/j.jmatprotec.2012.12.013 . hal-00806279

\section{HAL Id: hal-00806279 \\ https://hal.science/hal-00806279}

Submitted on 27 Mar 2014

HAL is a multi-disciplinary open access archive for the deposit and dissemination of scientific research documents, whether they are published or not. The documents may come from teaching and research institutions in France or abroad, or from public or private research centers.
L'archive ouverte pluridisciplinaire HAL, est destinée au dépôt et à la diffusion de documents scientifiques de niveau recherche, publiés ou non, émanant des établissements d'enseignement et de recherche français ou étrangers, des laboratoires publics ou privés. 


\title{
Cruciform shape benefits for experimental and numerical evaluation of sheet metal formability
}

Lionel Leotoing, Dominique Guines, Ibrahim Zidane, Eric Ragneau

Université Européenne de Bretagne, France, INSA-LGCGM-EA 3913

20 Av. des Buttes de Coësmes, CS70839, 35708 Rennes Cedex 7, France

Email: lionel.leotoing@insa-rennes.fr

\begin{abstract}
The optimization of sheet metal forming processes requires accurate evaluations of material forming abilities. This paper presents an original technique based on the use of a cruciform shape for experimental characterization and numerical prediction of forming limit curves. The whole forming limit diagram is covered with a unique geometry by controlling displacements in the two main directions of the cruciform shape. The test is frictionless and the influence of linear and non-linear strain paths can be easily studied. The modeling of the cruciform shape with the finite element method permits to plot forming limit curves without any calibration step, essential for the classical Marciniak-Kuczynski (M-K) model. Experimental and numerical results are presented for an aluminium alloy 5086. These results are respectively compared with the ones from classical techniques : Marciniak test and
\end{abstract}


numerical M-K model.

Keywords: Forming Limit Curves (FLCs); Cruciform specimen; Biaxial tensile test; M-K Model; Aluminium alloys

\section{Introduction}

Sheet metal forming is a widely used method for producing various components for different fields of application. In sheet metal forming operations, the sheet can be deformed only up to a certain limit. The ability of sheet metal to deform into desired shape without local necking or fracture is defined as its formability. Formability may depends on many factors like material properties or process parameters (strain paths, strain rate, temperature, ...). The design and optimization of forming operations with numerical simulation tools needs more and more accurate predictions of material formability in order to fully exploit its forming abilities. Thus, understanding and characterizing the formability of metal sheets are essential for controlling final product quality and then evaluating the success of the sheet forming operation, especially with the increasing use of aluminium alloys. Miller et al. (2000) have shown that these alloys exhibit generally low formability compared with typical mild steels.

The most popular technique to evaluate the formability of sheet metals is 
the forming limit diagram (FLD). A FLD is a major/minor strain diagram which can distinguish between safe points and necked or failed points. The transition from safe to failed points is defined by the forming limit curve (FLC). The determination of FLDs is a complex task and research on FLDs has always been the subject of extensive experimental, analytical or numerical studies. For experimental determination of forming limit curves, two main kinds of forming methods have been developed, the so-called out-of-plane stretching (e.g. Nakajima test) and the in-plane stretching (e.g. Marciniak test). For out-of-plane stretching, the blank is deformed under triaxial stress while during in-plane stretching, the sheet is under plane stress conditions in the central part. By forming a number of sheet specimens with varying widths, different deformation modes (strain states) are observed (Figure 1). 


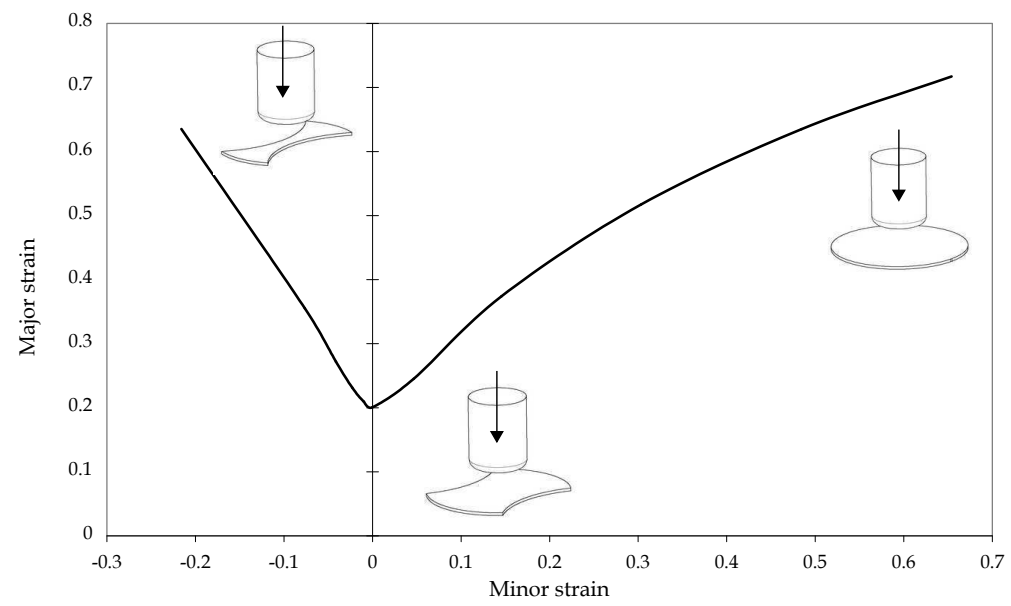

Figure 1: Exemple of Forming Limit Curve and Marciniak's specimens with varying widths

Despite some major drawbacks, these conventional tests are widely used. The main drawbacks are the use of a high number of specimens with different geometrical properties, the influence of friction and the description of forming limit curves for simplistic linear strain paths. Barata Da Rocha et al. (1984) have notably demonstrated that non-linear loadings, frequently encountered in industrial processes, have a great influence on level and shape of FLCs.

The Marciniak and Kuczynski model (known as the M-K model) is a widely used analytical tool which has undergone great improvement. However, for complex constitutive laws (like thermo-viscoplastic behaviours), the analytical M-K model does not work well because the inherent system equations cannot be easily resolved. Due to the developments in the methods 
of modeling and simulation, numerical predictions of FLCs have become more attractive. Petek et al. (2005) have selected the Finite Element (FE) method to model the Marciniak test and then simulate the necking process. This approach permits to reduce the experimental effort of formability characterization even if in this case the drawbacks of the Marciniak test are still present. With numerical methods, the limits of the analytical approaches can be overcome by implanting any complex constitutive law into FE code, as already explained by Zhang and present authors with the use of a FE geometrical model of the M-K model (Zhang et al. (2010)). Nevertheless, the initial geometrical imperfection factor in the $\mathrm{M}-\mathrm{K}$ model is uncertain. Its value can be adjusted by making the best fit between the numerical and experimental results or by making a microstructural analysis of the metallic sheet, as it is successfully used by Abedrabbo et al. (2007). Moreover, the choice of an appropriate constitutive law is a key to obtaining the practical prediction of FLCs.

In order to overcome the drawbacks of the above experimental and numerical methods, a cruciform shape could be an interesting alternative to characterize and predict forming limit curves. Yu et al. (2002) tried to propose a cruciform biaxial tensile specimen with a chamfer on the arms and the cen- 
tral region to reach limit states. The interest of the cruciform shape is clearly demonstrated in this study but no forming limit curves have been obtained with this specimen. Many authors intensively used cruciform specimens for various mechanical characterizations. Pascole and De Villiers (1973) have used a cruciform specimen to study the low cycle fatigue of steels, a similar shape has been used by Kelly (1976) to study creep failure. Yield criteria and hardening identifications have notably been carried out by Lin et al. (1993). In these studies, a low level of strain is generally reached in the central zone of the specimens, cruciform shape must be improved in order to observe high level of strains in the central region. Although cruciform specimens have been investigated quite extensively, Hannon and Tiernan (2008) mention that no standard geometry exists and the design of a dedicated specimen shape is still the main difficulty that restricts applications for the cruciform biaxial tensile test. The main advantage of this shape is that the strain path at the onset of necking is directly imposed by the control of the testing machine, independently on the specimen geometry. A unique geometry is then sufficient to cover the whole forming limit diagram, the influence of strain path can be easily studied by applying linear or non-linear loadings. Another benefit is that the test is frictionless, the formability is characterized without any 
influence of friction. Numerically, the use of the finite element method to model the cruciform shape can permit the implementation of complex mechanical behaviour in order to evaluate the influence of operating conditions like temperature or strain rate on the formability. Moreover for this numerical model, the calibrating step of the initial geometrical imperfection factor which is essential for M-K models, is unnecessary. A direct evaluation of the formability is possible with this predictive model and its experimental validation is made easier by the use of the same experimental cruciform shape with well-known boundary conditions.

In this paper, experimental results are first presented for an aluminium alloy 5086. This alloy possesses good welding characteristics, resistance to corrosion and formability properties. It is commonly used in aeronautics and marine. Then numerical predictions of formability are given for different implementations of material behaviours, the aim of this part is to show that a good correlation between experimental and numerical results exists if an accurate identification of the material behaviour is used, especially for high strains. Finally, a comparison between experimental and numerical results from the cruciform shape and conventional tools (Marciniak test and M-K model) is presented. 


\section{Experimental results}

\subsection{Specimen design}

A dedicated cruciform shape must be designed in order to observe the onset of necking in the central zone of the specimen and not in the arms or fillets of the specimen. This condition permits to control the strain path of the necking zone thanks to the displacements of the four actuators. From finite element simulations, different geometries have been investigated. The more effective and the more promising specimen shape (Figure 2) has been already optimized by present authors (Zidane et al. (2010)) in order to make efficient its use for a whole forming limit curve identification. The central region of the specimen is fabricated by using a digital numerical turninglathe, with a precision of $0.02 \mathrm{~mm}$ for the central thickness. 


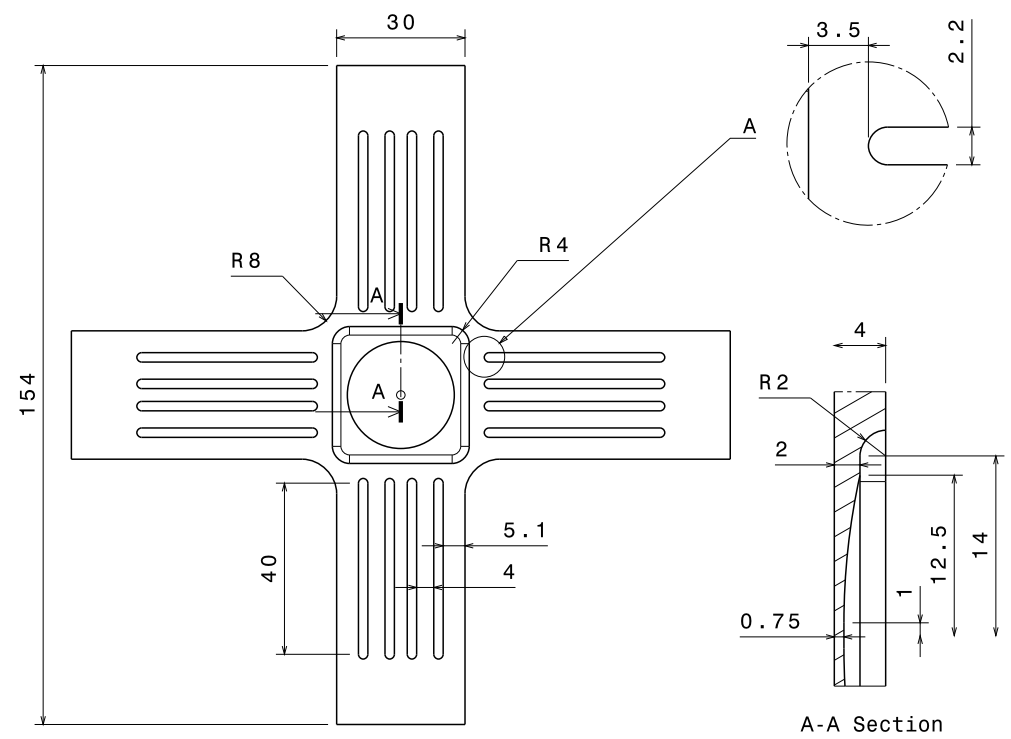

Figure 2: Cruciform shape

For this geometry, the strain path value at the central point of the specimen is directly linked to the velocity ratio of actuators. At the onset of necking, the value of the strain path remains almost constant for all speed ratios, as illustrated in figure 5 for three different strain path values (dashed curves). The evolution of the strain path is linear as it is observed in conventional tests of formability (Marciniak or Nakajima).

To test this specimen, a servo-hydraulic testing machine provided with four independent dynamic actuators is used (Figure 3). The center point of the specimen is always maintained stationary during the test thanks to an efficient servo-hydraulic control. For each actuator, the loading capacity is 
$50 K N$ and the maximum velocity can reach up $2 \mathrm{~m} / \mathrm{s}$.

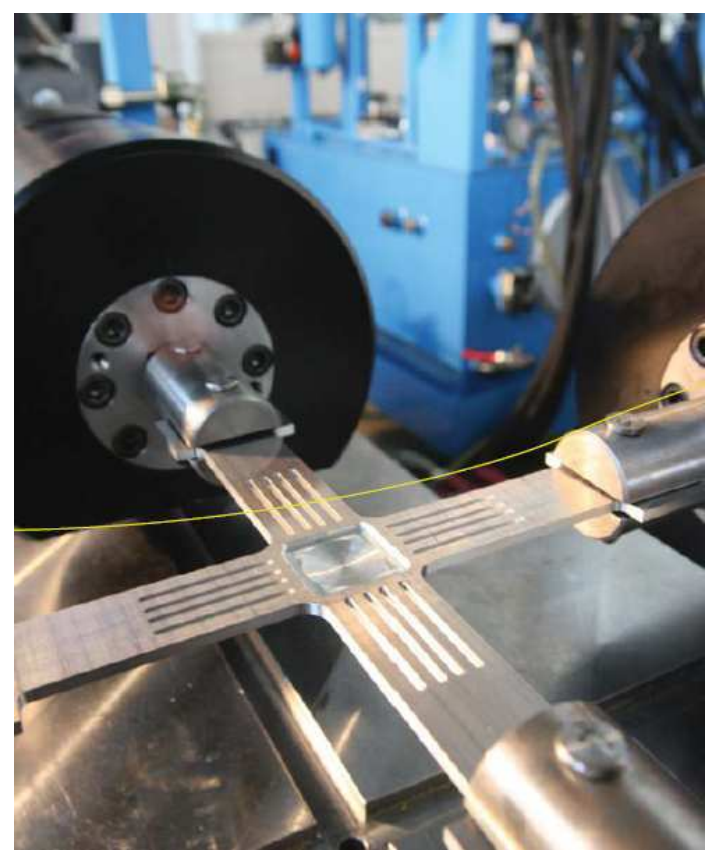

Figure 3: Cruciform specimen tested by a servo-hydraulic machine with four independent actuators

To cover the whole forming limit diagram, constant speeds are set on each axis of the cruciform specimen and the tested speed ratios are given in Table 1.

\begin{tabular}{l|cccccccccc}
\hline Axis 1(mm/s) & 1 & 1 & 1 & 1 & 1 & 1 & 1 & 1 & 1 & 1 \\
\hline Axis $2(\mathrm{~mm} / \mathrm{s})$ & 1 & 0.75 & 0.5 & 0.4 & 0.25 & 0.1 & 0 & -0.02 & -0.1 & free \\
\hline
\end{tabular}

Table 1: Constant speeds set on each axis of the cruciform specimen 


\subsection{Results}

The difficulty in identifying experimental forming limit curves lies in the choice of an appropriate criterion to detect the onset of necking. The international standard ISO 12004-2 can be applied using either the Nakajima or the Marciniak procedure. The limit strains that can be imposed on the material are determined through interpolation, using a "position-dependent" method. In this work, due to its simplicity and reproducibility, a "time-dependent" method is preferred and will be applied also to determine numerical forming limit curves. When necking occurs in a zone, a sharp change of strain can be observed, corresponding to the onset of a plastic instability. Outside the necking zone, the level of strains remains stable and constant. When the equivalent plastic strain increment ratio between a point located inside the necking zone (zone 1 in Figure 4) and outside the necking zone (zone 2 in Figure 4) has reached a critical value, the time step of onset of necking is then defined and the corresponding major and minor strains in zone 1 represents one point of the FLC. The strain fields on the surface of the specimen are measured thanks to a Digital Image Correlation (DIC) technique associated with a high resolution camera. 


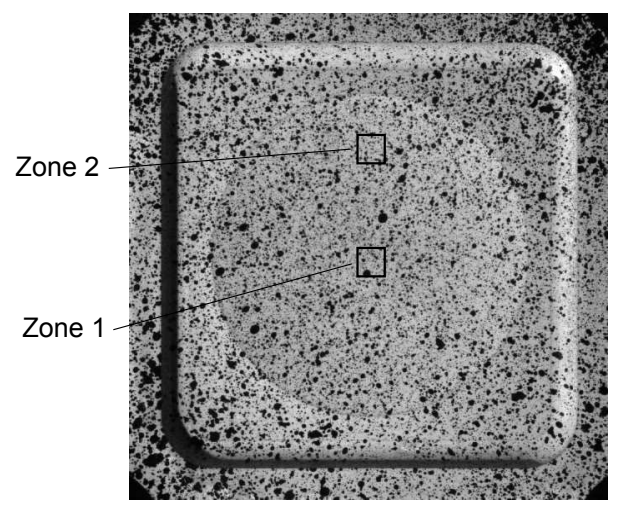

Figure 4: Zones 1 and 2 of the cruciform specimen

For the cruciform shape, the procedure to calibrate this critical value is described by Zidane et al. (2010). A critical equivalent plastic strain increment ratio of 8 between zones 1 and 2 was chosen by identifying the time step of onset of a bifurcation point on the evolution of the equivalent plastic strain inside the necking zone (zone 1). The experimental forming limit points for the different strain paths are shown in Figure 5. As it is illustrated in this figure, it is confirmed that the initial stage of fracture takes place in the centre of the specimen. The experimental necking directions are repeatable. For the cruciform shape, the necking direction is perpendicular to major strain direction in uniaxial tension, the same observation is made with the Marciniak test for this aluminium alloy. For the equibiaxial strain mode, the direction is oblique $\left(45^{\circ}\right)$ to major strain direction for the cruci- 
form shape whereas for the Marciniak test, the direction is also oblique but the angle presents more fluctuations.
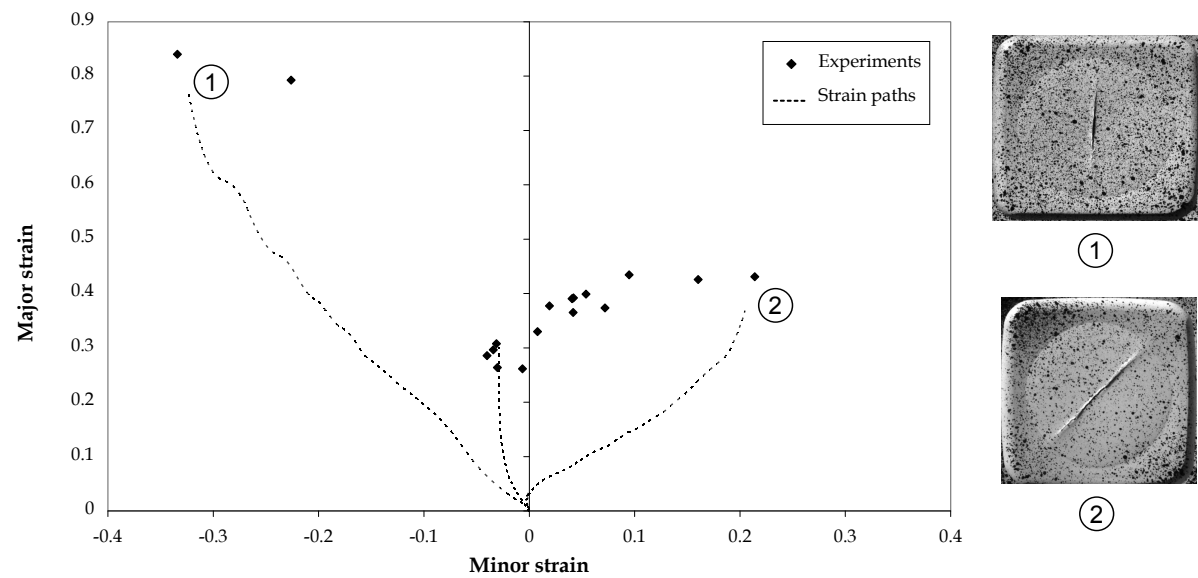

(2)

Figure 5: Experimental forming limit points for AA5086 and two examples of fracture in the centre of the specimen

\section{Numerical predictions}

This section presents the numerical model used to predict FLCs and some results for different descriptions of the mechanical behaviour of the metallic sheet.

\subsection{Model}

Based on the cruciform specimen shape (Figure 2), the finite element method is applied to build a new predictive model for forming limit curves. 
Due to the symmetrical properties of the specimen, only one-quarter is modeled (Figure 6). For meshing, tetrahedral elements are applied and a refined mesh is adopted where strain localization may appear (central zone, fillet, grooves).

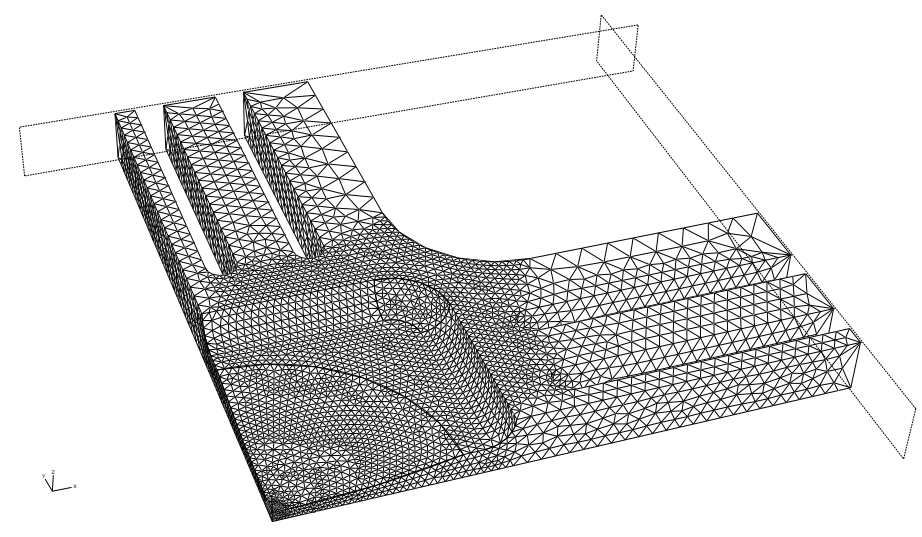

Figure 6: Mesh of the cruciform specimen

The elastic part is described by Hooke's model (Young modulus of 67290 MPa and Poisson ratio of 0.3 ). Different hardening laws are proposed to model the plastic behaviour of the material : $(\mathbf{L})$ the classical power law of Ludwick (Eq. 1), (V2) a saturation law based on the Voce's formulation (Eq. 2) and (V1) an intermediate additive law made up of a saturation term and a linear one (Eq. 3).

$$
\bar{\sigma}=\bar{\sigma}_{0}+\mathrm{K} \bar{\varepsilon}^{\mathrm{n}}
$$




$$
\begin{gathered}
\bar{\sigma}=\bar{\sigma}_{0}+\mathrm{Q} \sqrt{1-\mathrm{e}^{-\mathrm{B} \bar{\varepsilon}}} \\
\bar{\sigma}=\bar{\sigma}_{0}+\mathrm{Q}\left(1-\mathrm{e}^{-\mathrm{B} \bar{\varepsilon}}\right)+\mathrm{H} \bar{\varepsilon}
\end{gathered}
$$

In equations from (1) to (3), $\bar{\sigma}$ and $\bar{\varepsilon}$ are respectively the equivalent stress and the equivalent plastic strain. Constitutive model parameters are constants identified from a mono-axial test on a constant section AA5086 specimen. For the three hardening laws ( $\mathbf{L}, \mathbf{V} \mathbf{2}$ and $\mathbf{V} \mathbf{1})$, the results of the identification are respectively presented in tables 2,3 and 4 . These laws are implemented in the finite element code ABAQUS by means of the Fortran subroutine UHARD.

\begin{tabular}{ccc}
\hline $\bar{\sigma}_{0}(M P a)$ & $K(M P a)$ & $n$ \\
\hline 125.9 & 447.1 & 0.41
\end{tabular}

Table 2: Constitutive model parameters for the Ludwick's law $(\mathbf{L})$

\begin{tabular}{ccc}
\hline $\bar{\sigma}_{0}(M P a)$ & $Q(M P a)$ & $B$ \\
\hline 130.2 & 300.4 & 3.94 \\
\hline
\end{tabular}

Table 3: Constitutive model parameters for the Voce's law (V2) 


\begin{tabular}{cccc}
\hline $\bar{\sigma}_{0}(M P a)$ & $Q(M P a)$ & $B$ & $H(M P a)$ \\
\hline 160.0 & 166.8 & 15.0 & 161.9 \\
\hline
\end{tabular}

Table 4: Constitutive model parameters for the additive Voce's law (V1)

A comparison between the three identified hardening laws is proposed in Figure 7. In this figure, one can see the very good correlation between the three approaches and the experimental values for an equivalent strain value between 0 and 20\%. For larger values of the equivalent strain, a clear discrepancy appears between the power law and the two Voce's formulations. For (V2), a saturation is observed and the evolution of (V1) is very close to (V2) despite its linear term. Finally, The mono-axial test does not permit to choose the appropriate hardening law for this material. For predictive models of forming limit curves, hardening laws must be defined accurately for equivalent plastic strain generally larger than $50 \%$ which is impossible with the mono-axial tensile test. Nevertheless, in the following section, the effects of the choice of the hardening law on the evaluation of the forming limit curves will be quantified. 


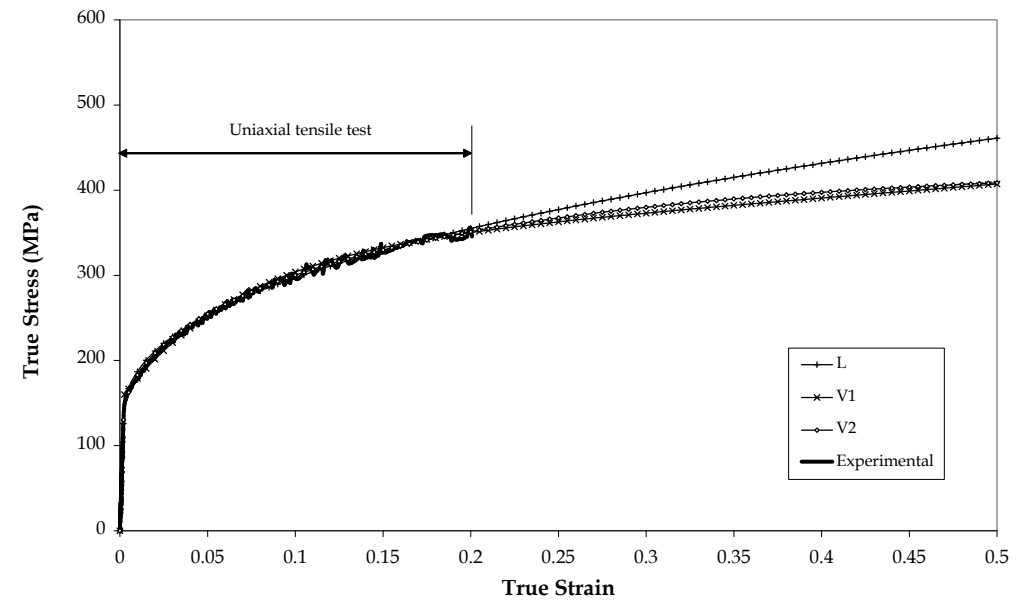

Figure 7: Identification of $\mathbf{L}, \mathbf{V} \mathbf{2}$ and $\mathbf{V} \mathbf{1}$ hardening laws

The choice of the yield criterion for this predictive model is also discussed hereafter. The isotropic Mises's criterion is compared with the classical anisotropic Hill48 yield criterion. The anisotropy of this alloy is relatively low in the plane of the sheet and Hill48 yield criterion can give an acceptable description of this anisotropy. For Hill48 yield criterion, the equivalent stress $\bar{\sigma}$ is expressed by a quadratic function of the following type :

$$
2 \bar{\sigma}^{2}=F\left(\sigma_{y}-\sigma_{z}\right)^{2}+G\left(\sigma_{z}-\sigma_{x}\right)^{2}+H\left(\sigma_{x}-\sigma_{y}\right)^{2}+2 L \sigma_{y z}^{2}+2 M \sigma_{z x}^{2}+2 N \sigma_{x y}^{2}
$$

where $F, G, H, L, M$ and $N$ are constants specific to the state of anisotropy of the material. The direction $x$ is the rolling direction, $y$ the transverse direction and $z$ the normal direction. Its ease of use permits to 
evaluate the influence of an anisotropic criterion on the determination of the forming limit curves. The parameters of the Hill48 criterion have been identified from Lankford's coefficients and are given in table 5.

\begin{tabular}{cccccc}
\hline$F$ & $G$ & $H$ & $L$ & $M$ & $N$ \\
\hline 0.7 & 0.637 & 0.363 & 1.5 & 1.5 & 1.494 \\
\hline
\end{tabular}

Table 5: Hill48 yield parameters

\subsection{Numerical FLCs}

Different displacements should be imposed in the two perpendicular directions in order to obtain different points belonging to the forming limit curve. The procedure already used to detect the experimental limit strains is applied to identify the numerical forming limit curves. Figure 8 shows the impact of the hardening law and yield criterion on the prediction of FLCs. 


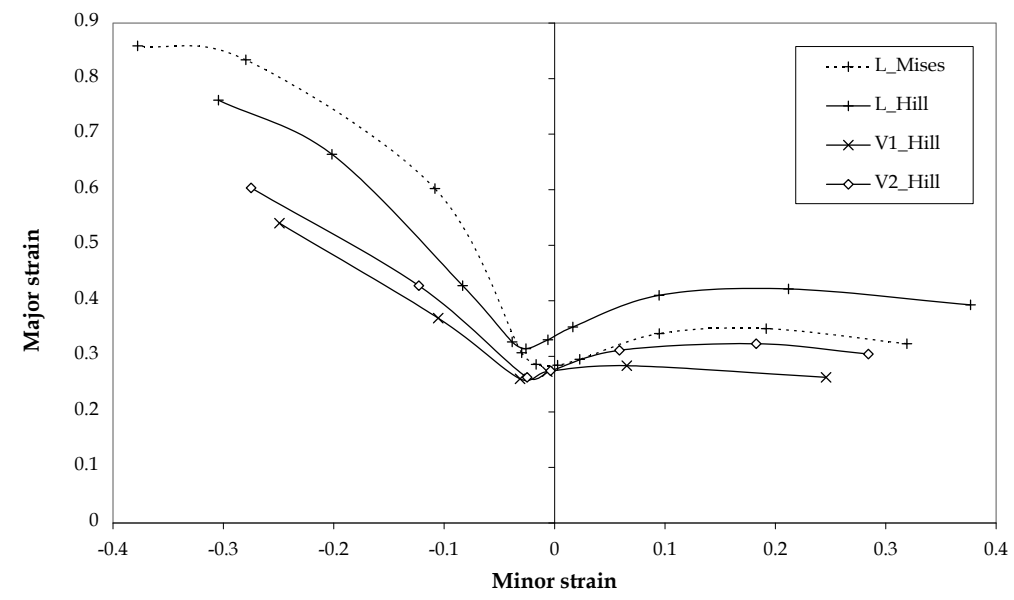

Figure 8: Influence of hardening law and yield criterion on numerical FLCs

As seen in figure 8, the two Voce's hardening laws (V1) and (V2) associated with the Hill48 yield criterion predict a lower forming limit curve as compared to the power law of Ludwick $(\mathbf{L})$, associated with the same yield criterion. This difference between the predictions of the two models was also reported by Abedrabbo et al. (2006) for calculations based on the M-K model. The influence of the yield criterion is only studied for the Ludwick's law, Figure 8 shows a noticeable difference of behaviour between left-hand side and right-hand side of the Forming Limit Diagram. In the left-hand side, Hill48 yield criterion predicts a lower FLC as compared to isotropic Mises criterion, which is the opposite for the right-hand side. By means of these numerical predictions with different hardening laws and yield criteria, it is 
observed that the modeling of material behaviour greatly influences the level and shape of predictive FLCs. An experimental verification of these results is proposed hereafter.

\subsection{Comparison with experimental results}

Figure 9 shows a comparison between experimental and numerical FLCs for Ludwick's law with Hill48 and Mises criterion. The conservative FLCs predicted by the two Voce models are not presented in this figure. As could be seen from this plot, the correlation between experimental and numerical results is very good for the right-hand side of the forming limit curve, especially for the Hill48 criterion. In this case, taking an anisotropic yield criterion into consideration improves considerably the accuracy of the numerical predictions. These results demonstrate the pertinency and the efficiency of the numerical model based on the cruciform shape to evaluate forming limits, without any calibration procedure as it will be discussed in the next section. 


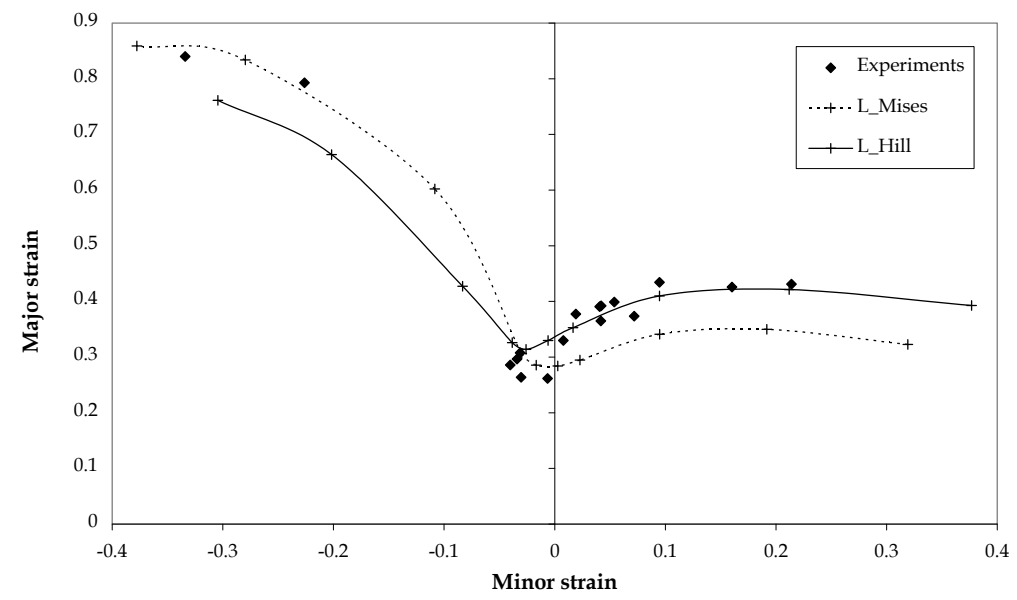

Figure 9: Comparison between experimental and numerical FLCs

\section{Discussion}

The aim of this section is to compare the numerical and experimental results from the cruciform shape with the results obtained with widespread tools like Marciniak test for experimental FLCs and M-K model for analytical and numerical ones.

\subsection{Comparison with experimental results from Marciniak test}

A Marciniak test setup associated with a digital image correlation technique has been developed to experimentally evaluate sheet formability, this setup has been already described by Zhang et al. (2010). In this work, a similar time-dependent method based on a critical increment strain ratio is 
used. The comparison between forming limits from this Marciniak test and from the tensile biaxial test is presented in Figure 10.

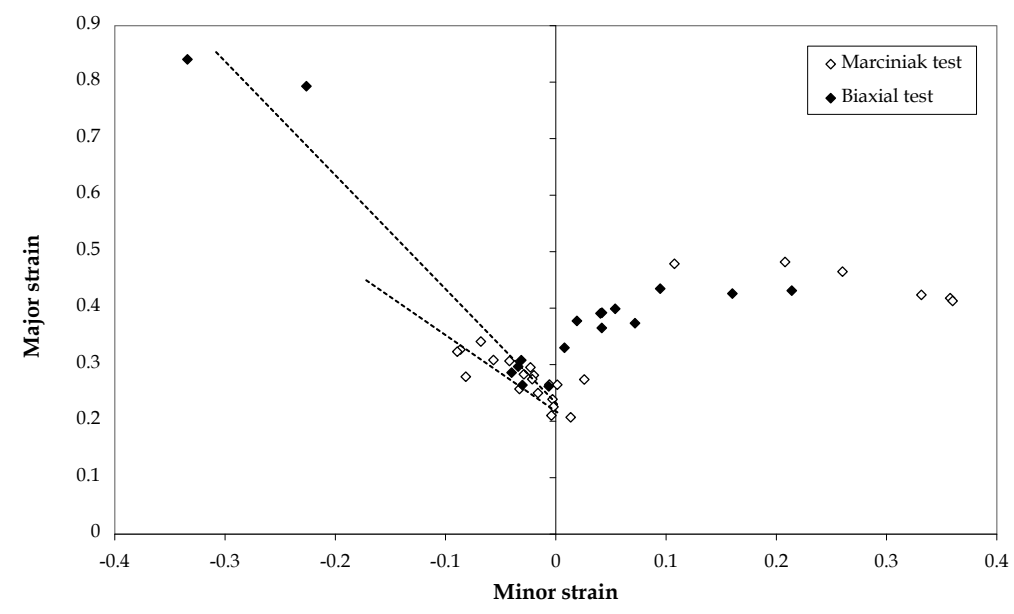

Figure 10: Experimental FLCs from Marciniak test and biaxial test

For the right-hand side of the forming limit diagram, despite some discrepancies due to the variability encountered in forming limits evaluation, the two experimental procedures give the same results. For the left-hand side and more especially for strain path corresponding to uniaxial tension, the forming limits from cruciform shapes are much higher. This behaviour was also observed for the previous numerical results. For the cruciform shape, we can suppose the existence of a mechanism which stabilize the deformation and then enhance the formability. Several mechanisms of stabilization are mentioned by Emmens and Van Den Boogaard (2009) and discussed for the 
specific case of incremental sheet forming. In our case, only the bendingunder-tension mechanism due to the dissymmetry of the cruciform specimen could contribute to the stabilization of the deformation. Nevertheless, the bending observed during the tests is slight and can not explain such a discrepancy for the left-hand side. The evolution of major and minor strains before necking for the two tests can give a better explanation for the formability increase measured in the biaxial test. During an uniaxial tension test, diffuse and localized necking are distinguished (Figure 11).

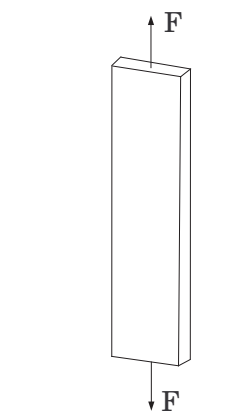

(a)

Uniform deformation

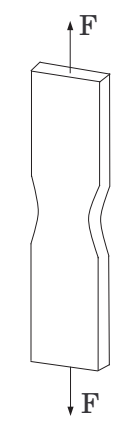

(b)

Diffuse necking

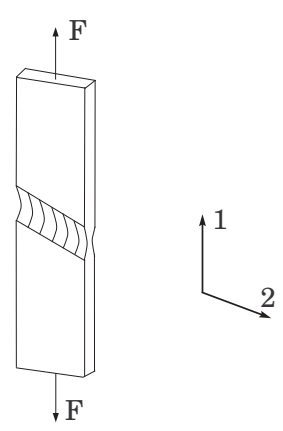

(c)

Localized necking

Figure 11: Diffuse and localized necking

Diffuse necking is characterized by contraction strains in both the width and the thickness directions of the specimen, the size of a diffuse necking is of the order of the specimen width. Diffuse necking develops gradually and a significant extension is still possible after the onset of diffuse necking. 
Finally, a condition is reached where a sharp localized necking occurs. With localized necking, the strain along the necking band is zero and the thickness strain is exclusively provided by the remaining in-plane strain. The size of the necking band is of the order of the sheet thickness. The same phenomenon is observed in the Marciniak test when using narrow specimens (Figure 12-(a)) for the uniaxial tension strain path.

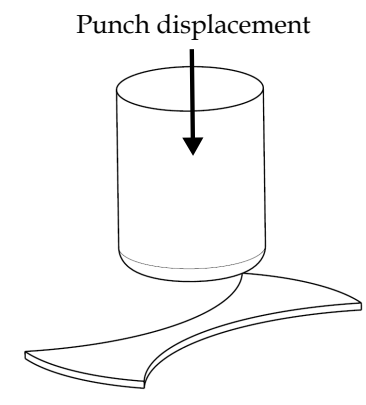

(a)

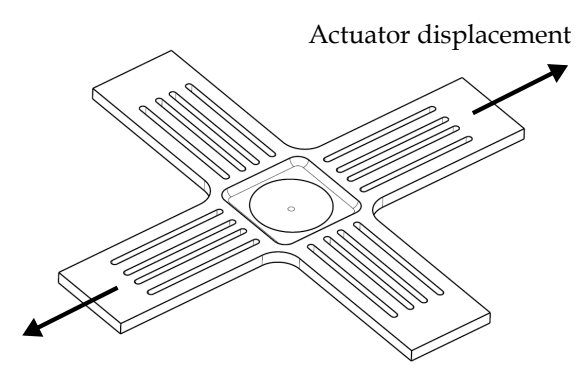

(b)

Figure 12: Specimens and imposed displacements for an uniaxial tension strain path, for Marciniak (a) and cruciform specimen (b)

Figure 13 illustrates the onset of diffuse and localized necking during a Marciniak test by following the evolution of major and minor strain. After a steady stage of major strain increase and minor strain decrease, diffuse necking develops and a considerable acceleration of the evolutions of in-plane strains is observed. Localized necking clearly appears for a zero evolution of 
the minor strain.

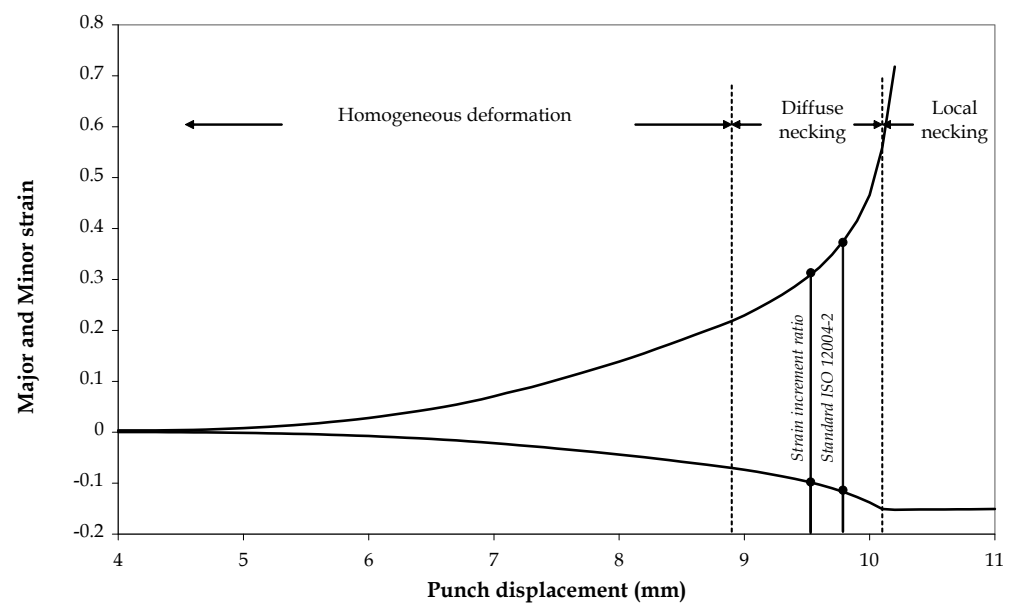

Figure 13: Evolution of minor and major strains for Marciniak test for the strain path corresponding to uniaxial tension

In industrial stamping, as mentioned by Aretz (2004), the maximum allowable strains are given by localized necking. Many criteria to detect the onset of necking have been already presented and discussed in the literature and even if a standard is established, the discussion is still opened. In Figure 13, the forming limits given by our critical increment strain ratio and the ones given by the international standard ISO 12004-2 are represented. For the two criteria, necking is detected during the diffuse stage, the increment strain ratio criterion is more conservative. The same evolution of the major and minor strains can be plotted for the cruciform shape (Figure 12-(b)) for 
the strain path corresponding to uniaxial tension. As shown in Figure 14, the diffuse necking is not really observed. The localized necking corresponding to a zero contraction of the minor strain clearly appears after a steady evolution of in-plane strains. The forming limits detected by the critical increment strain ratio are then very close to the localized necking zone.

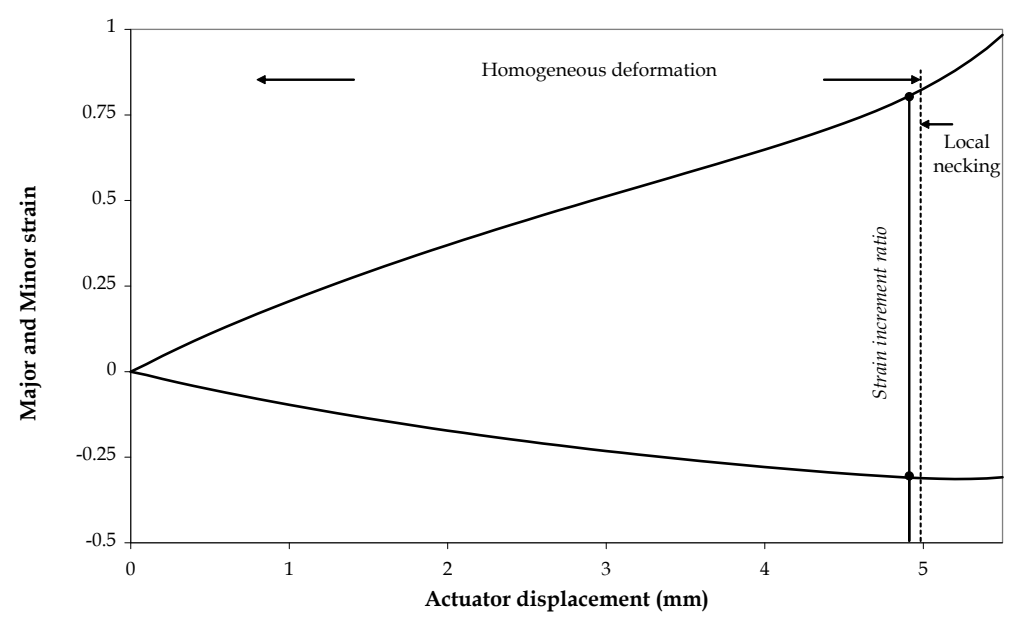

Figure 14: Evolution of minor and major strains for cruciform shape for the strain path corresponding to uniaxial tension

Figures 13 and 14 clearly show that the mechanisms of the necking onset is different in the two tests. This difference can explain the increase of formability observed with the cruciform shape. Firstly, for the cruciform shape the forming limit criterion detects the onset of localized necking whereas for the Marciniak test it is activated during the diffuse necking stage 
prior to localized necking. Secondly, the appearance of diffuse necking probably accelerates the onset of localized necking in the narrow specimen of the Marciniak test. For the cruciform shape, the in-plane strain evolutions are stable and directly linked to the actuator displacements, which delays the onset of localized necking.

For the left-hand side of the forming limit diagram, the two tests give different forming limits and it is difficult to assert that one prediction is better than the other. Nevertheless, the shape of the narrow specimens used in Marciniak or Nakajima tests is debatable, even if it permits to reach strain paths in uniaxial tension, this shape is not always representative of the geometry of industrial parts zones with the same strain path. For a complex part, in a zone where uniaxial tension is observed, large width in the direction of the minor strain could stabilize and delay the onset of necking as it is observed for the cruciform shape.

\subsection{Numerical $M-K$ model}

Many analytical or numerical results based on M-K models have been already presented in the literature. It would be interesting to compare the formability predictions of the numerical model of the cruciform shape with the results of a classical M-K model. For this comparison, a geometrical 
M-K model already presented by Zhang et al. (2010) is built in the FE code ABAQUS. Due to symmetry, only one half of the entire model in the thickness is considered and the sheet is meshed by hexahedral elements. The boundary conditions are imposed by displacement constraints in main directions of the sheet. The previous identified constitutive models can be easily implemented by means of the subroutine UHARD. Similarly as the analytical M-K model, an initial defect in the sheet is characterized by two different zone thicknesses $: t_{a}$ and $t_{b}$ in zone $a$ and $b$ respectively (Figure 15).

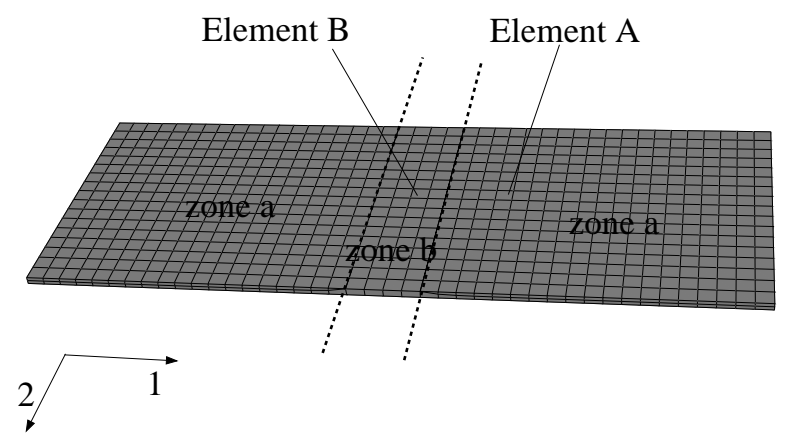

Figure 15: Finite Element M-K model

The initial imperfection of the sheet thickness is characterized by the initial imperfection factor $f_{0}=t_{b} / t_{a}$. The main drawback of the M-K model is that the results are highly sensitive to this geometrical imperfection. The imperfection can be caused by various factors such as local grain size variation, 
texture, alloy elements or thickness variation but in many studies, the value of $f_{0}$ is arbitrary fixed (a value of 0.98 is usual). A good approach consists in adjusting the imperfection by fitting theoretical results and experimental ones. One experimental point is sufficient to adjust the initial imperfection but the choice of strain path influences the plot of the forming limit curve, as illustrated in Figure 16.

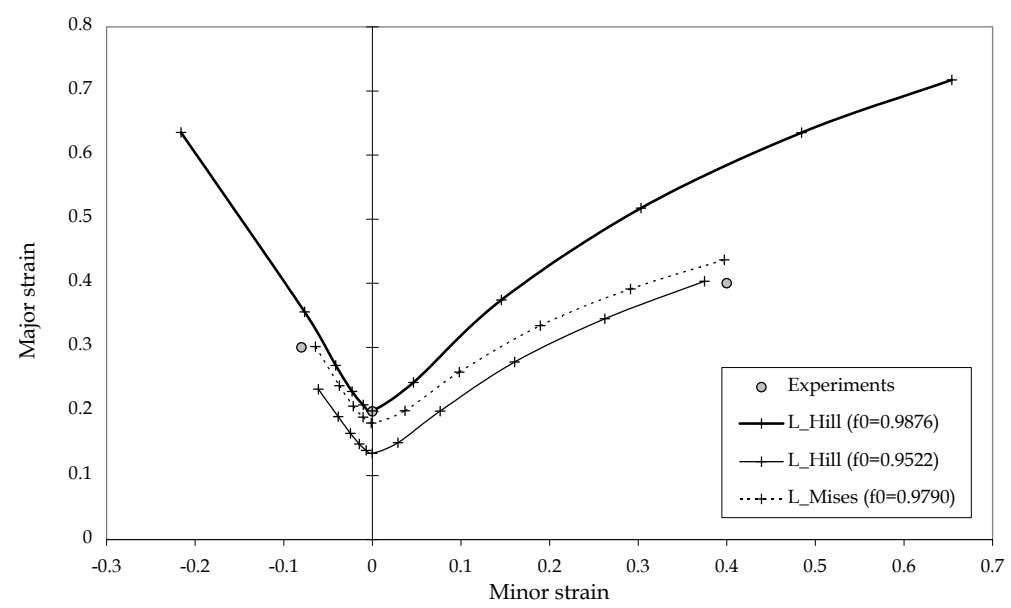

Figure 16: Influence of the geometrical imperfection value on the formability prediction ok M-K model

In Figure 16, for the same material behaviour ( $\mathbf{L}$ and Hill48 yield criterion), the calibration of $f_{0}$ in biaxial tension gives a value close to 0.95 whereas for plane strain (zero minor strain) the value is 0.9876 . The calibration is made with the experimental results of the Marciniak test. For the M-K 
model, the $\mathbf{L}$ hardening law associated with the mises criterion $\left(f_{0}=0.979\right)$ gives the best fitting with the three experimental points represented in the figure. Figure 16 clearly underlines the difficulties in using a M-K model as a predictive model for plotting forming limit curves. The calibration is essential and strongly depends on the choice of the experimental point. The results are also sensitive to the constitutive model but this remark has been already made for the numerical model based on the cruciform shape. Figure 17 shows a comparison between numerical FLCs from cruciform shape and M-K model (calibrated with Marciniak test results) for the $\mathbf{L}$ hardening law associated with Hill48 and Mises yield criterion. For the two material behaviours implemented in the finite element code, the major discrepancies between the two models are mainly observed for positive minor strain with the Hill criterion and for negative minor strain with the Mises criterion. The difference between the two predictive models, especially for the left-hand side could be reduced by calibrating the M-K model with the results of the biaxial tensile test. The choice of the yield criterion is then crucial for the two models. 


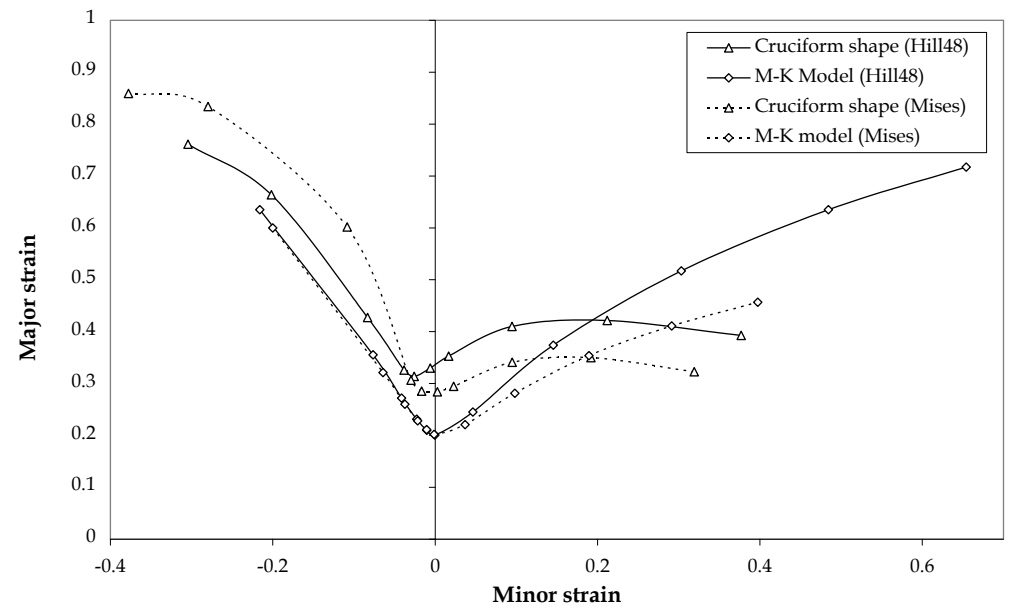

Figure 17: Comparison of the two numerical models for $\mathbf{L}$ hardening law associated with Hill48 or Mises yield criterion

The reliability of a predictive numerical model for forming limit curves needs an accurate description of the material behaviour for large strains. The main advantage of the numerical model based on the cruciform shape is the removal of the calibration step which requires necessarily experimental results.

\section{Conclusion}

The use of a cruciform shape can be an interesting alternative method to plot experimental or numerical forming limit curves. The main advantage of this shape is that the strain paths are directly imposed by the testing 
machine. For linear strain paths, the comparison of experimental results with the ones from a classical Marciniak test shows a very good correlation. Tests with non-linear strain paths can provide adapted forming limit curves to evaluate material formability for complex parts. The test is frictionless and the coupled influence of operating conditions like temperature or strain rate can be easily evaluated. Numerically, the current research shows the importance of using an accurate mechanical model of the material to predict FLCs. Nevertheless, the FE model based on the cruciform shape gives a direct evaluation of formability without any calibration step, contrary to the classical M-K model. The cruciform shape can contribute to a better prediction of forming limit curves by evaluating the effects of various parameters, not easily quantified with the conventional tests.

\section{References}

Abedrabbo, N., Pourboghrat, F., Carsley, J., 2006. Forming of aluminium alloys at elevated temperatures - part 2 : Numerical modeling and experimental verification. International Journal of Plasticity 22, 342-373.

Abedrabbo, N., Pourboghrat, F., Carsley, J., 2007. Forming of AA5182-o 
and AA5754-o at elevated temperatures using coupled thermo-mechanical finite element models. International Journal of Plasticity 23, 841-875.

Aretz, H., 2004. Numerical restrictions of the modified maximum force criterion for prediction of forming limits in sheet metal forming. Modelling and Simulation in Materials Science and Engineering 12, 677-692.

Barata Da Rocha, A., Barlat, F., Jalinier, J., 1984. Prediction of the forming limit diagrams of anisotropic sheets in linear and non-linear loading. Materials Science and Engineering 68, 151-164.

Emmens, W., Van Den Boogaard, A., 2009. An overview of stabilizing deformation mechanisms in incremental sheet forming. Journal of Materials Processing Technology 209, 3688-3695.

Hannon, A., Tiernan, P., 2008. A review of planar biaxial tensile test systems for sheet metal. Journal of materials processing technology 198, 1-8.

Kelly, D., 1976. Problems in creep testing under biaxial stress systems. Journal of strain analysis $11,1-6$.

Lin, S., Ding, J., Zbib, H., 1993. Characterization of yield surfaces using bal- 
anced biaxial tests of cruciform plate specimen. Scripta metallica material $28(5), 617-622$.

Miller, W., Zhuang, L., Bottema, J., Wittebrood, A., De Smet, P., Haszler, A., Vieregge, A., 2000. Recent development in aluminium alloys for the automotive industry. Materials Science and Engineering A 280, 37-49.

Pascole, K., De Villiers, J., 1973. Low cycle fatigue of steels under biaxial straining. Journal of strain analysis $2(2), 117-126$.

Petek, A., Pepelnjak, T., Kuzman, K., 2005. An improved method for determining forming limit diagram in the digital environment. Journal of Mechanical Engineering 51, 330-345.

Yu, Y., Wan, M., Wu, X.-D., Zhou, X.-B., 2002. Design of a cruciform biaxial tensile specimen for limit strain analysis by FEM. Journal of Materials Processing Technology 123, 67-70.

Zhang, C., Leotoing, L., Zhao, G., Guines, D., Ragneau, E., 2010. A methodology for evaluating sheet formability combining the tensile test with the m-k model. Materials Science and Engineering A 528, 480-485.

Zidane, I., Guines, D., Leotoing, L., Ragneau, E., 2010. Development of 
an in-plane biaxial test for forming limit curve (FLC) characterization of metallic sheets. Measurement Science and Technology 21, 1-11. 